\title{
IN-PLANE FREE VIBRATIONS OF SYMMETRICALLY LAMINATED RECTANGULAR COMPOSITE
}

\section{PLATES}

\begin{tabular}{|l|l|l|}
\hline Kumar Pankaj & Ujjwal Bhardwaj & Priyanka Singh \\
Department of Mechanical & Department of Civil Engineering, \\
Engineering, I.T.S Engineering & I.T.S Engineering College, Greater \\
$\begin{array}{l}\text { College, Greater Noida, U.P. 201308, } \\
\text { India } \\
\text { pankajrajput2@gmail.com }\end{array}$ & $\begin{array}{l}\text { Noida, U.P. 201308, India } \\
\text { bhardwaj.civil@gmail.com }\end{array}$ & $\begin{array}{l}\text { Dronacharya College of Engineering, } \\
\text { Gurgoan, Haryana 122001, India } \\
\text { sweetpriti.singh@gmail.com }\end{array}$ \\
\hline
\end{tabular}

Abstract: This work presents accurate upper-bound solutions for free in-plane vibrations of single-layer laminated rectangular composite plates with an arbitrary combination of clamped and free boundary conditions. A Ritz method with a simple, stable and computationally efficient set of trigonometric functions is developed to obtain accurate in-plane modal properties of rectangular plates with arbitrary uniform elastic edge restraints. Inplane natural frequencies and modes shapes are calculated by the TRM. Reliability of the method is assessed by comparison with known solutions for square composite plates. Influence of degree of orthotropy, aspect ratio and boundary conditions upon the in-plane vibration behavior are discussed. Effects of uniform elastic spring stiffness on the in-plane natural frequencies and modal shapes are also presented.

Keywords:Laminates, Composites, In-plane vibration, Ritz method, Trigonometric set

\section{INTRODUCTION}

Composites are engineering materials made from two or more materials with significantly different properties which remain distinct on a macroscopic level within the entirety of the structure. It can be defined as a mixture of two or more mechanically separable materials that when combine, give properties superior to the properties of the individual components. Composite materials like carbon-fiber reinforced polymer, plywood, aramid fiber laminates and fiberglass laminates have been used in a multitude of applications. The mechanical properties of composites are generally not isotropic, but orthotropic. Composites serve as lighter substitutes for their metallic, isotropic counterparts. This is especially apparent in the aerospace industry.

Free vibration analysis of composite plates plays a key role in many engineering applications, such as civil, aerospace, marine, automotive structural components, electronic circuit boards, energy scavenging devices and optical and mechanical equipments. Vibration is totally a mechanical phenomenon whereby oscillations occur about an equilibrium point. And free vibration occurs when a mechanical system is set off with an initial input and then allowed to vibrate freely. In- 
ELK

Asia Pacific Journals

plane vibration is different from the flexural vibration. Here in-plane means only two components is considered for the vibration analysis i.e. vibrating body is said to be in plane only.

Although relatively less references can be found in the wide literature to deal with in-plane vibration of rectangular plates, confident prediction of membrane modal behavior of plate systems can be of key importance in some engineering applications, like vibration transmission in built-up structures and/or vibration excitation due to fluid turbulent boundary layer or forces not perfectly perpendicular to the middle plane.

In the past literatures there are many methods discussed to analyze the in-plane free vibrations of rectangular plates. D.J. Gorman. (June 2006) [1] developed the exact solutions for the free inplane vibration of rectangular plates with two opposite plate edges are given either type of simple support, the other two edges being given any combination of classical edge conditions. The first of simple support is characterized by null displacement parallel to the edge as well as normal stress perpendicular to the edge and the second type of support, where the displacement normal to the edge is fully restrained as well as the shear stress along the edge. Each type of
ELK Asia Pacific Journals - Special Issue

ISBN: 978-81-930411-4-7

simple support is shown to be analogous to the well-known simple support edge conditions encountered in the flexural vibration analysis of rectangular plates. Y.F. Xing, B. Liu. (March 2009) [2] derived all possible exact solutions for the free in-plane vibrations of a rectangular plate by using a direct separation of variables approach. Using the Rayleigh quotient variational principle, all classical boundary conditions including two distinct types of simple support boundary conditions are formulated undergoing in-plane free vibrations for rectangular plate.

A numerical approximate method is required when any arbitrary combinations of supporting edges or lay-ups other than cross-ply are involved. From the literature review it is found that there are mainly four methods have been adopted for achieving analytical type in-plane vibration solutions of plates. These are the Ritz method, the Kantorovich method, the superposition method and the Fourier series method. The approaches in which summation of continuous differentiable functions are assumed as the displacement solutions for the problem. Beslin O, Nicolas (1997) [15] comparative study has been done on the use of trigonometric set over polynomial with some remarkable advantages. 
ELK

Asia Pacific Journals

As per the literature survey and of the best knowledge Kobayashi et al. (1988) [4] published the first Ritz-based results for in-plane natural frequencies and mode shapes of rectangular plates. They used a series of product of power functions for the admissible functions. and discussed a limited number of computed results for point-supported isotropic plates for the inplane vibration analysis. Bardell et al. (1996) [5] did their work on isotropic plates and calculated the first six frequency parameters with all edges simply supported, clamped or free using a set of orthogonal polynomials in conjunction with Hermitecubics. Singh and Muhammad (May 2004) [6] developed a modified form of the Ritz method for the analysis of in-plane modes of isotropic non-rectangular plates. Woodcock et al. (2008) [7] did the first attempt in providing specific information about the influence of angle of orthotropy on the in-plane free motion of rectangular plates. They used the Ritz formulation along with Hamilton principle to study the effect of ply orientation on the in-plane vibrations of composite plates. The natural frequencies were calculated by adopting simple polynomial functions as admissible solutions. Lorenzo Dozio (October 2010) [17] used the Ritz method using a set of trigonometric functions to obtain accurate in-plane modal properties of rectangular plates
ELK Asia Pacific Journals - Special Issue

ISBN: 978-81-930411-4-7

with arbitrary non-uniform elastic edge restraints. Lorenzo Dozio (October 2010) [3] presented the accurate upper-bound solutions for free in-plane vibrations of single-layer and symmetrically laminated rectangular composite plates with an arbitrary combination of clamped and free boundary conditions. In-plane natural frequencies and modes shapes are calculated by the Ritz method with a simple, stable and computationally efficient set of trigonometric functions. Influence of fiber orientation, stacking sequence, degree of orthotropy, aspect ratio and boundary conditions upon the in-plane vibration behavior are also discussed.

Du et al. (2007) [14] developed an analytical method for the in-plane frequencies and mode shapes of isotropic rectangular plates with classical boundary conditions and elastically restrained edges. It assumes displacement solutions as a linear combination of double Fourier series with supplementary terms such that the assumed solution exactly satisfies both the governing differential equations and the boundary conditions.

Gorman (2004a, 2004b, 2005 and 2009) [10, 11, $12,13]$ introduced the superposition method as a valuable analytical-type tool to predict in-plane natural frequencies and mode shapes of isotropic and especially orthotropic plates. Highly accurate 
ELK

Asia Pacific Journals

frequency parameters and shapes of symmetric, anti-symmetric and symmetric-anti-symmetric modes are presented for fully clamped plates with various aspect ratios and orthotropic elastic properties. It provides solutions which satisfy exactly the governing differential equation throughout the entire domain of the plate. Boundary conditions are satisfied to any desired degree of accuracy by increasing the number of terms in the solution.

As the previous review demonstrates, not much approximate solutions are available for free inplane vibration of generally orthotropic multilayered and laminated plates of rectangular platform with any combination of clamped and free boundary conditions. Also, very little research has done to find the accurate in-plane modal properties of square/rectangular plates with uniform elastic edge restraints. In order to achieve the above mentioned goals, the Ritz method has been adopted due to its computational simplicity, wide flexibility, high reliability and computational efficiency.

\section{FORMULATION}

Consider a rectangular symmetrically laminated composite plate of dimensions $a \times b$. Where length is a andwidth $\mathrm{b}$ lying in the $(x, y)$ plane corresponding to the middle surface of the plate.
ELK Asia Pacific Journals - Special Issue

ISBN: 978-81-930411-4-7

The plate consists of $\mathrm{N}_{\mathrm{l}}$ layers. The material used is assumed to be homogeneous and orthotropic. The thickness of the plate is denoted by $h$ and the $\mathrm{kth}$ layer is denoted by $\mathrm{h}_{\mathrm{k}}$. The origin of the $(x, y)$ coordinate system is assumed to be located at the plate center and the kth layer is located between the points $\mathrm{z}=\mathrm{z}_{\mathrm{k}}$ and $\mathrm{z}=\mathrm{z}_{\mathrm{z}+1}$ in the thickness direction. Displacements of the composite plate in the $\mathrm{x}$ and $\mathrm{y}$ direction are indicated with $\mathrm{u}=\mathrm{u}(\mathrm{x}, \mathrm{y}, \mathrm{t})$ and $\mathrm{v}=\mathrm{v}(\mathrm{x}, \mathrm{y}, \mathrm{t})$, respectively. An arbitrary combination of clamped (C) and free (F) boundary conditions are considered. Throughout the paper, a four-letter symbolic notation is used for describing the type of boundaries. For example, a CFCF plate has clamped edges at $\mathrm{x}=$ $\pm \mathrm{a} / 2$ and free edges at $y= \pm b / 2$.

A general support conditions are also considered, which are represented by massless normal and tangential springs along each edge.The stiffness value of each restraining spring is denoted by $k_{\gamma}^{\delta}$ where $\gamma=1,2,3,4$ refers to the plate edge (i.e., location) and $\delta=U, V$ refers to the corresponding degree of freedom (i.e., direction).And the plate boundaries are numbered counterclockwise beginning from the edge $x=-a / 2$. For instance, $k_{1}^{U}$ and $k_{1}^{V}$ are used to indicate the distributed stiffness for the tangential and normal springs, respectively, along the bottom edge of the plate.Noting that, in this 
ELK

Asia Pacific Journals

formulation, the stiffness for each of the elastic restraints is allowed to vary arbitrarily along an edge, i.e., $k_{\gamma}^{\delta}=k_{\gamma}^{\delta}(\eta)$ for $\gamma=1,3$ and $k_{\gamma}^{\delta}=k_{\gamma}^{\delta}(\varepsilon)$ for $\gamma=2,4$.

\section{Strain And Kinetic Energy}

The strain energy of the rectangular plate is given by the following expression as per [3].

$\mathrm{U}=\frac{1}{2} \int_{-a / 2-b / 2}^{+a / 2+b / 2}\left[\begin{array}{l}A_{11}\left(\frac{\partial u}{\partial x}\right)^{2}+A_{22}\left(\frac{\partial v}{\partial y}\right)^{2}+2 A_{12} \frac{\partial u}{\partial x} \frac{\partial v}{\partial y} \\ +2\left(A_{16} \frac{\partial u}{\partial x}+A_{26} \frac{\partial v}{\partial y}\right)\left(\frac{\partial u}{\partial y}+\frac{\partial v}{\partial x}\right)+A_{66}\left(\frac{\partial u}{\partial y}+\frac{\partial v}{\partial x}\right)^{2}\end{array}\right] \mathrm{dx} \mathrm{dy}$

Where the In-plane rigidities are given as:

$$
A_{i j}=\sum_{k=1}^{N_{l}} Q_{i j}^{(k)}\left(Z_{k+1}-Z_{k}\right)
$$

The kinetic energy of the rectangular plate is given by the following expression:

$\mathrm{T}=\frac{1}{2} m_{0} \int_{-a / 2}^{+a / 2} \int_{-b / 2}^{+b / 2}\left[\left(\frac{\partial u}{\partial t}\right)^{2}+\left(\frac{\partial v}{\partial t}\right)^{2}\right] \mathrm{dx} \mathrm{dy}$

Where, $\quad m_{0}=\sum_{k=1}^{N_{l}} \rho^{(k)}\left(Z_{k+1}-Z_{k}\right)$

$\rho^{(k)}$ is the density of the kth layer.

In order to treat these equations taking the nondimensional coordinates as:
ELK Asia Pacific Journals - Special Issue

ISBN: 978-81-930411-4-7

$\xi=\frac{2 x}{a}, \eta=\frac{2 y}{b}$

Consider a harmonic motion with frequency $\omega$, i.e.

$$
\begin{aligned}
& u(\xi, \eta, t)=u(\xi, \eta) e^{i w t}=u e^{i w t} \\
& v(\xi, \eta, t)=v(\xi, \eta) e^{i w t}=v e^{i w t}
\end{aligned}
$$

The maximum strain energy and the maximum kinetic energy stored in the plate during in-plane stretching in a vibratory cycle are calculated as:

$$
\begin{aligned}
& \mathrm{U}_{\max }=\frac{1}{2} \int_{-1-1}^{+1+1} \int_{11}\left[\begin{array}{l}
A_{11}\left(\frac{b}{a}\right)\left(\frac{\partial u}{\partial \xi}\right)^{2}+A_{22}\left(\frac{a}{b}\right)\left(\frac{\partial v}{\partial \eta}\right)^{2}+2 A_{12} \frac{\partial u}{\partial \xi} \frac{\partial v}{\partial \eta}+2 A_{16} \frac{\partial u}{\partial \xi} \frac{\partial u}{\partial \eta} \frac{\partial v}{\partial \xi}+2 A_{26}\left(\frac{a}{b}\right) \frac{\partial u}{\partial \eta} \frac{\partial v}{\partial \eta}+2 A_{26} \frac{\partial v}{\partial \xi} \frac{\partial v}{\partial \eta} \\
+A_{66}\left(\frac{a}{b}\right)\left(\frac{\partial u}{\partial \eta}\right)^{2}+A_{66}\left(\frac{b}{a}\right)\left(\frac{\partial v}{\partial \xi}\right)^{2}+2 A_{66} \frac{\partial u}{\partial \eta} \frac{\partial v}{\partial \xi}+
\end{array}\right] \mathrm{d} \xi \mathrm{d} \eta \\
& \mathrm{T}_{\max }=\frac{1}{2} \frac{m_{0} a b}{4} \omega^{2} \int_{-1-1}^{+1+1} \int_{-1}^{2}\left(u^{2}+v^{2}\right) \mathrm{d} \xi \mathrm{d} \eta
\end{aligned}
$$

The energy functional of the system is determined as:

$$
\Pi=\mathrm{U}_{\max }-\mathrm{T}_{\max }
$$

\section{Ritz Trigonometric Set}

The Ritz approximation method is used to solve the problem and so it is employed by assuming the following solutions for the amplitudes $u$ and $v$ : 
ELK

Asia Pacific Journals

$$
\begin{aligned}
& u(\xi, \eta)=\sum_{m=1}^{M} \sum_{n=1}^{N} a_{m n} \phi_{m}^{u}(\xi) \phi_{n}^{u}(\eta) \\
& v(\xi, \eta)=\sum_{m=1}^{M} \sum_{n=1}^{N} b_{m n} \phi_{m}^{v}(\xi) \phi_{n}^{v}(\eta)
\end{aligned}
$$

Where $a_{m n}$ and $b_{m n}$ are unknown coefficients and $\varphi_{m}^{u}(\xi), \varphi_{n}^{u}(\eta), \varphi_{m}^{v}(\xi)$ and $\varphi_{n}^{v}(\eta)$ are appropriate admissible functions which satisfies at least the geometrical boundary conditions of the problem under consideration. In this related problem, the following displacement boundary conditions apply for each edge.

\section{$u=v=0 \quad:$ Clamped Edge}

\section{u, v not restrained : Free Edge}

Since homogeneous condition is considered, the relation involved for both $u$ and $v$ along one edge, it is assumed as:

$$
\begin{aligned}
& \phi_{m}^{u}(\xi)=\phi_{m}^{v}(\xi)=\phi_{m}(\xi) \\
& \phi_{n}^{u}(\eta)=\phi_{n}^{v}(\eta)=\phi_{n}(\eta)
\end{aligned}
$$

The trigonometric admissible function first proposed by Beslin and Nicolas [13] for flexural vibration of Kirchhoff plates are here applied:

$\phi_{m}(\xi)=\sin \left(a_{m} \xi+b_{m}\right) \sin \left(c_{m} \xi+d_{m}\right)$

Similarly, $\phi_{n}(\eta)$ can be defined accordingly where $\xi$ and $m$ are replaced by $\eta$ and $n$, respectively.
ELK Asia Pacific Journals - Special Issue

ISBN: 978-81-930411-4-7

$\phi_{n}(\eta)=\sin \left(a_{n} \eta+b_{n}\right) \sin \left(c_{n} \eta+d_{n}\right)$

Where the coefficients $a_{i}, b_{i}, c_{i}$ and $d_{i}$ are listed in Table 3.1

\begin{tabular}{|c|c|c|c|c|}
\hline $\mathbf{I}$ & $\mathbf{a}_{\mathbf{i}}$ & $\mathbf{b i}_{\mathbf{i}}$ & $\mathbf{c}_{\mathbf{i}}$ & $\mathbf{d i}$ \\
\hline $\mathbf{1}$ & $\pi / 4$ & $3 \pi / 4$ & $\pi / 4$ & $3 \pi / 4$ \\
\hline $\mathbf{2}$ & $\pi / 4$ & $3 \pi / 4$ & $-\pi / 2$ & $-3 \pi / 2$ \\
\hline $\mathbf{3}$ & $\pi / 4$ & $-3 \pi / 4$ & $\pi / 4$ & $-3 \pi / 4$ \\
\hline $\mathbf{4}$ & $\pi / 4$ & $-3 \pi / 4$ & $\pi / 2$ & $-3 \pi / 2$ \\
\hline$>\mathbf{4}$ & $\pi / 2(i-4)$ & $\pi / 2(i-4)$ & $\pi / 2$ & $\pi / 2$ \\
\hline
\end{tabular}

Table 2.1. coefficients of Ritz trigonometric set

A subset of $\phi_{m}(\xi)=p_{m}(x)$ is plotted in Fig. 2.1 where functions of increasing order are arranged in a matrix-like form. It is seen from the Fig. 1 that the first and third functions $\phi_{1}(\xi)$ and $\phi_{3}(\xi)$ allow a non-zero displacement at $\xi=-1$ and $\xi=1$, respectively. Whilesecond and fourth trigonometric functions $\phi_{2}(\xi)$ and $\phi_{4}(\xi)$, allow a free slope at the opposite edges $\xi= \pm 1$. These can be interpreted as required degrees of freedom at the corner nodes of the plate. 
ELK

Asia Pacific Journals
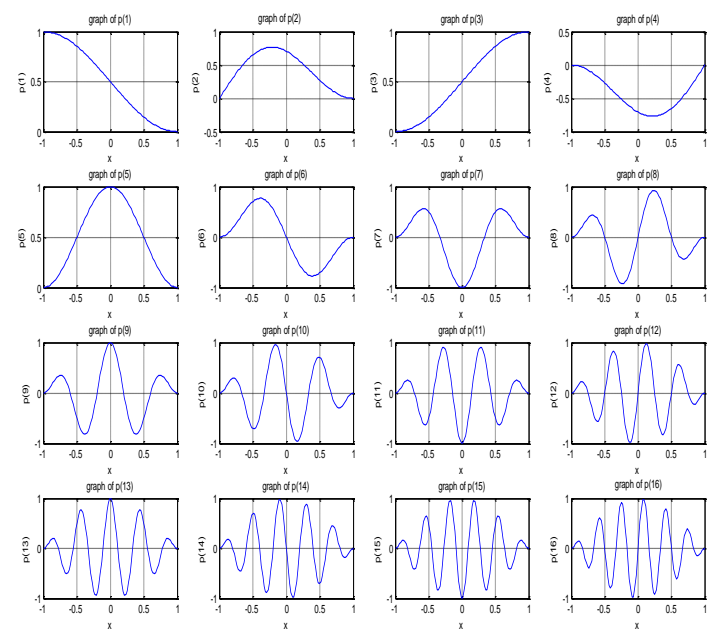

Fig. 2.1. The first 16 functions of Ritz trigonometric set

The functions $\phi_{1}(\eta), \ldots, \phi_{4}(\eta)$ are arranged in a similar fashion for $\eta= \pm 1$. As such, the first four functions $\phi_{1}, \ldots, \phi_{4}$ permit one to easily satisfy free and clamped boundary conditions by selecting a proper combination among them. The four combinations of boundary conditions are considered in this work are tabulated in Table 2.1

For case $m, n>4$ all trigonometric functions have zero deflection and slope at both ends $\xi, \eta= \pm 1$ and the order of a function is seen related to the number of oscillations inside the domain.This offers a great numerical stability because of its well-conditioned mass and stiffness matrices are obtained here, even considering very high order functions $(m, n \gg 1)$, i.e. $\mathrm{M}, \mathrm{N}$ can be taken very
ELK Asia Pacific Journals - Special Issue

ISBN: 978-81-930411-4-7

large and no special attention to round-off errors is required.

A further attractive property of the present trigonometric set has in its simple algebra and calculus. First, a very low number of operations are needed contrary to other Ritz functions such as polynomials to manage them and this number does not increase with order. Second, all integrals involved in calculations of mass and stiffness matrices can be obtained analytically without restoring to recursive formulas. Last, using simple trigonometric identities, it can be shown that a huge number of elements of such integrals are identically zero. As a consequence, the mass and stiffness matrices tend to be highly sparse. , even when it is large can be solved by very efficient method using MATLAB.

Ritz approximations for $u$ and $v$, is solved numerically for the resulting sparse eigenvalue problem in a very efficient way using, iterative projection methods of Arnoldi type. An algorithmic variant of the Arnoldi process called the Implicitly Restarted Arnoldi method is used here as implemented in MATLAB via the built-in eigs function. 
ELK

Asia Pacific Journals

Boundary Condition (I)

\begin{tabular}{|c|c|c|c|c|}
\hline $\begin{array}{c}\text { BOUNDARY } \\
\text { CONDITIONS }\end{array}$ & $\boldsymbol{\Phi}_{1}$ & $\boldsymbol{\Phi}_{2}$ & $\boldsymbol{\Phi}_{3}$ & $\boldsymbol{\Phi}_{4}$ \\
\hline FF & - & $\cdot$ & $\cdot$ & $\cdot$ \\
\hline FC & - & $\cdot$ & - & $\cdot$ \\
\hline CF & - & $\cdot$ & $\cdot$ & $\cdot$ \\
\hline CC & - & $\cdot$ & - & $\cdot$ \\
\hline
\end{tabular}

Table 2.2. Combination of first four functions in the trigonometric set to satisfy the related boundary condition

Combinations of first four functions are to satisfy the related boundary condition. Bullets in a row indicate which functions are retained in the final set.

\section{Boundary Condition (II)}

Classical boundary conditions can be easily recovered by accordingly setting the values of the related springs. A free condition along one edge, designated by the symbol $\mathrm{F}$, is obtained by setting to zero both the corresponding normal and tangential spring. Infinitely large value of both sets of springs allows simulating an essentially clamped (C) edge. Two distinct sets of simple support boundary conditions are physically realizable in the case of in-plane vibration analysis of rectangular plates. The first type of simple support condition can be obtained by specifying infinite stiffness for the tangential springs and zero stiffness for the normal springs.
ELK Asia Pacific Journals - Special Issue

ISBN: 978-81-930411-4-7

Zero and infinite values for the tangential and normal springs, respectively, allow simulating the $\mathrm{S}_{2}$-type boundary condition.

In a similar fashion, three types of elastically restrained edges, indicated by the symbols $\overline{E_{1}}$, $\overline{E_{2}}$ and $\overline{E_{1}^{2}}$, are here introduced. $\overline{E_{1}}$-type edges are characterized by elastically restrained displacement parallel to the edge and free displacement normal to the edge. On the contrary, support type $\overline{E_{2}}$ allows free parallel displacement along the edge and elastically restrained displacement normal to the edge. When both normal and parallel displacements along the edge are elastically restrained, the edge support is denoted by $\overline{E_{1}^{2}}$.

\section{Coupled Eigenvalue Problem (I)}

The coefficient $a_{m n}$ and $b_{m n}$ can be obtained by taking the extremum of the energy functional $\pi$ is given as:

$\frac{\partial \Pi}{\partial a_{m n}}=0, \frac{\partial \Pi}{\partial b_{m n}}=0$

After putting gives the following coupled eigenvalue equations: 
ELK

Asia Pacific Journals

$$
\begin{aligned}
& \sum_{r=1}^{M} \sum_{s=1}^{N}\left[K_{m n r s}^{u u} a_{r s}+K_{m n r s}^{u v} b_{r s}-\omega^{2} M_{m n r s} a_{r s}\right]=0 \\
& \sum_{r=1}^{M} \sum_{s=1}^{N}\left[K_{m n r s}^{v u} a_{r s}+K_{m n r s}^{v v} b_{r s}-\omega^{2} M_{m n r s} b_{r s}\right]=0
\end{aligned}
$$

The elements of the plate stiffness and mass matrices are as follow:

$$
\begin{aligned}
& K_{m n r s}^{u u}=A_{11}\left(\frac{b}{a}\right) I_{m r}^{11} I_{n s}^{00}+A_{66}\left(\frac{a}{b}\right) I_{m r}^{00} I_{n s}^{11}+A_{16}\left(I_{m r}^{10} I_{n s}^{01}+I_{m r}^{01} I_{n s}^{10}\right) \\
& K_{m r s}^{u v}=A_{12} I_{m r}^{10} I_{n s}^{01}+A_{16}\left(\frac{b}{a}\right) I_{m r}^{11} I_{n s}^{00}+A_{26}\left(\frac{a}{b}\right) I_{m r}^{00} I_{n s}^{11}+A_{66} \sigma_{m r}^{01} I_{n s}^{10} \\
& K_{m r r s}^{v u}=A_{12} I_{m r}^{01} I_{n s}^{10}+A_{16}\left(\frac{b}{a}\right) I_{m r}^{11} I_{n s}^{00}+A_{26}\left(\frac{a}{b}\right) I_{m r}^{00} I_{n s}^{11}+A_{66} \sigma_{m r}^{10} I_{n s}^{01} \\
& K_{m n r s}^{u u}=A_{22}\left(\frac{a}{b}\right) I_{m r r}^{00} I_{n s}^{11}+A_{66}\left(\frac{b}{a}\right) I_{m r}^{11} I_{n s}^{00}+A_{26}\left(I_{m r}^{10} I_{n s}^{01}+I_{m r}^{01} I_{n s}^{10}\right) \\
& M_{m n r s}=\frac{m_{0} a b}{4} I_{m r}^{00} I_{n s}^{00}
\end{aligned}
$$

In which

$$
I_{m r}^{\alpha \beta}=\int_{-1}^{+1} \frac{d^{\alpha} \phi_{m}}{d \xi^{\alpha}} \frac{d^{\beta} \phi_{r}}{d \xi^{\beta}} d \xi \quad I_{n s}^{\alpha \beta}=\int_{-1}^{+1} \frac{d^{\alpha} \phi_{n}}{d \eta^{\alpha}} \frac{d^{\beta} \phi_{s}}{d \eta^{\beta}} d \eta
$$

are the integrals of the derivatives of order $\alpha$ and $\beta$ of the trigonometric functions.

\section{Coupled Eigenvalue Problem (II)}

New coupled eigenvalue equations after considering elastic boundary are following

$$
\begin{aligned}
& \sum_{r=1}^{M} \sum_{s=1}^{N}\left[K_{m n r s}^{u u} a_{r s}+K_{m n r s}^{u v} b_{r s}-\omega^{2} M_{m n r s} a_{r s}\right]=0 \\
& \sum_{r=1}^{M} \sum_{s=1}^{N}\left[K_{m n r s}^{v u} a_{r s}+K_{m n r s}^{v v} b_{r s}-\omega^{2} M_{m n r s} b_{r s}\right]=0
\end{aligned}
$$

ELK Asia Pacific Journals - Special Issue

ISBN: 978-81-930411-4-7

When elastic boundaries are considered, coupled eigenvalue equations will be formulated as simple elemental equation and few expressions are modified as and rest will remain like that only:

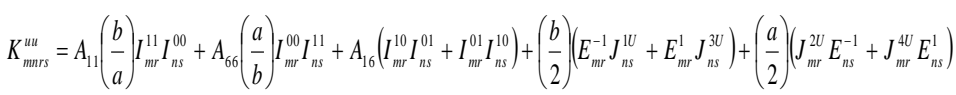

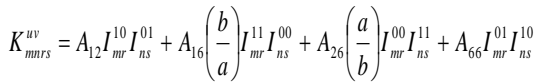

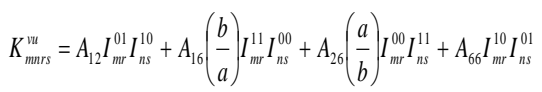

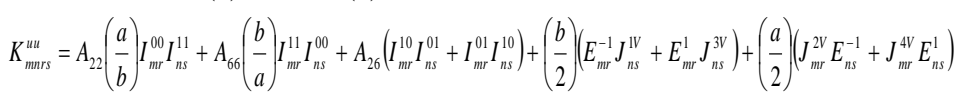

$$
\begin{aligned}
& M_{m n r s}=\frac{m_{0} a b}{4} I_{m r}^{00} I_{n s}^{00}
\end{aligned}
$$

Where

$$
\begin{aligned}
& J_{m r}^{\gamma \delta}=\int_{-1}^{+1} k_{\gamma}^{\delta}(\xi) \varphi_{m}(\xi) \varphi_{r}(\xi) d \xi \\
& J_{n s}^{\gamma \delta}=\int_{-1}^{+1} k_{\gamma}^{\delta}(\eta) \varphi_{n}(\eta) \varphi_{s}(\eta) d \eta \\
& E_{m r}^{\xi_{0}}=\varphi_{m}\left(\xi_{0}\right) \varphi_{r}\left(\xi_{0}\right) d \xi E_{n s}^{\eta_{0}}=\varphi_{n}\left(\eta_{0}\right) \varphi_{s}\left(\eta_{0}\right) d \eta \\
& J_{n s}^{\gamma \delta}=k_{\gamma}^{\delta} I_{i j}^{00}
\end{aligned}
$$

In simplified matrix form for the MATLAB implementation the coupled eigenvalue equations can be written as: 
ELK

Asia Pacific Journals

$\left.\left[K_{m n r s}^{u u}\right\rfloor a\right]+\left[K_{m n r s}^{u v}\right\rfloor[b]-\omega^{2}\left[M_{m n r s} \llbracket[a]=0\right.$

$\left.\left[K_{m n r s}^{v u}\right] a\right]+\left[K_{m n r s}^{v v}\right][b]-\omega^{2}\left[M_{m n r s}\right\rfloor[b]=0$

Results are obtained by adopting a square selection strategy, where the same number of terms $M=N$ is used in the series expansion, with no regard to symmetry.

\section{RESULTS}

In this section,several plate problems involving different combinations of boundary conditions and complicating factors have been solved by TRM (Trigonometric Ritz Method) and analysis has been done to focus on single-layer composite plates made of an isotropic/orthotropic material. First, to check the accuracy of the applied method validation of the results are presented in the tabular form. After that, this method is more expended to the next level another kind of elastic boundary conditions are considered and parametric studies are done by using data in tabular form and graphs are also drawn to analyze it better.

\section{Validation of the method}

For the sake of comparison with the previous references and validity of the work few works are done on the single layer composite plates. First a
ELK Asia Pacific Journals - Special Issue

ISBN: 978-81-930411-4-7

square single-layered composite plate (i.e. $\mathrm{b} / \mathrm{a}=1$ ) is taken into consideration where ratio of elastic modulus is $E_{2} / E_{1}=1.5 \& 2.5$. The angle of orthotropy $\theta$ in the following tabulated results will vary from $0^{\circ}$ to $90^{\circ}$ with $15^{\circ}$ increments. The CCCC and FFFF boundary conditions are considered for the comparison of the results and validity of the work.

\begin{tabular}{|c|c|c|c|c|}
\hline 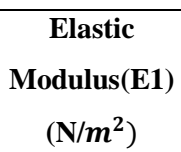 & $\begin{array}{l}\text { Passion's } \\
\text { Ratio (v) }\end{array}$ & $\begin{array}{c}\text { Thickness(h) } \\
\text { (mm) }\end{array}$ & $\begin{array}{l}\text { Length } \\
\text { (a) } \\
\text { (m) }\end{array}$ & $\begin{array}{c}\text { Density } \\
\text { (rho) } \\
\left(\mathrm{Kg} / \mathrm{m}^{3}\right)\end{array}$ \\
\hline $70 \mathrm{e} 9$ & 0.3 & 2.5 & 1 & 2700 \\
\hline
\end{tabular}

Table 3.1. Material properties and dimensions of the composite plate

For the sake of comparison with data provided in Ref.3, an orthotropic material with the following properties is utilized in Table 3.1.

$$
v_{12} v_{21}=v^{2}, \quad G_{12}=\frac{\sqrt{E_{1} E_{2}}}{2\left(1+\sqrt{v_{12} v_{21}}\right)}
$$

The properties used to calculate in-plane nondimensional frequency parameter is given in the Table 3.1. Results are presented in the form of the non-dimensional in-planefrequency parameter is given as, $\lambda=\frac{\omega a}{2} \sqrt{\frac{\rho\left(1+\sqrt{v_{12} v_{21}}\right)}{E_{1}}}$ 
ELK

Asia Pacific Journals

\begin{tabular}{|c|c|c|c|c|c|c|c|}
\hline \multirow{2}{*}{\multicolumn{2}{|c|}{ (Degree) }} & \multicolumn{3}{|c|}{$\begin{array}{c}\text { FFFF(b/a=1) } \\
\text { E2/E1 } 1=1.5\end{array}$} & \multicolumn{3}{|c|}{$\begin{array}{c}\text { FFFF(b/a=1) } \\
\text { E2/E1 }=2.5\end{array}$} \\
\hline & & \multirow{2}{*}{$\begin{array}{l}\text { Ref.3 } \\
1.265\end{array}$} & \multirow{2}{*}{$\begin{array}{r}\text { Present } \\
1.3473\end{array}$} & \multirow{2}{*}{$\begin{array}{l}\text { Error (\%) } \\
6.50592885\end{array}$} & \multirow{2}{*}{$\begin{array}{l}\text { Ref.3 } \\
1.2906\end{array}$} & \multirow{2}{*}{$\begin{array}{l}\text { Present } \\
1.4588\end{array}$} & \multirow{2}{*}{$\begin{array}{c}\text { Error (\%) } \\
13.032698\end{array}$} \\
\hline & $\begin{array}{l}\text { FIRST } \\
\text { MODE }\end{array}$ & & & & & & \\
\hline & $\begin{array}{l}\text { SECOND } \\
\text { MODE }\end{array}$ & 1.2831 & 1.4387 & 12.1268802 & 1.4529 & 1.6924 & 16.4842728 \\
\hline \multirow{2}{*}{15} & $\begin{array}{l}\text { FIRST } \\
\text { MODE }\end{array}$ & 1.2736 & 1.3164 & 3.36055276 & 1.3103 & 1.3762 & 5.02938258 \\
\hline & $\begin{array}{l}\text { SECOND } \\
\text { MODE }\end{array}$ & 1.2764 & 1.455 & 13.9924788 & 1.3929 & 1.7414 & 25.019743 \\
\hline \multirow{2}{*}{30} & $\begin{array}{l}\text { FIRST } \\
\text { MODE }\end{array}$ & 1.2655 & 1.2717 & 0.48992493 & 1.3562 & 1.2697 & 6.37811532 \\
\hline & $\begin{array}{l}\text { SECOND } \\
\text { MODE }\end{array}$ & 1.2943 & 1.4705 & 13.6135363 & 1.3586 & 1.7854 & 31.4146916 \\
\hline \multirow{2}{*}{45} & $\begin{array}{l}\text { FIRST } \\
\text { MODE }\end{array}$ & 1.2609 & 1.2532 & 0.61067491 & 1.345 & 1.232 & 8.40148699 \\
\hline & $\begin{array}{l}\text { SECOND } \\
\text { MODE }\end{array}$ & 1.3076 & 1.4745 & 12.7638422 & 1.3904 & 1.795 & 29.0995397 \\
\hline \multirow{2}{*}{60} & $\begin{array}{l}\text { FIRST } \\
\text { MODE }\end{array}$ & 1.2655 & 1.2717 & 0.48992493 & 1.3562 & 1.2697 & 6.37811532 \\
\hline & $\begin{array}{l}\text { SECOND } \\
\text { MODE }\end{array}$ & 1.2943 & 1.4705 & 13.6135363 & 1.3586 & 1.7854 & 31.4146916 \\
\hline \multirow{2}{*}{75} & $\begin{array}{l}\text { FIRST } \\
\text { MODE }\end{array}$ & 1.2736 & 1.3164 & 3.36055276 & 1.3103 & 1.3762 & 5.02938258 \\
\hline & $\begin{array}{l}\text { SECOND } \\
\text { MODE }\end{array}$ & 1.2764 & 1.455 & 13.9924788 & 1.3929 & 1.7414 & 25.019743 \\
\hline \multirow{2}{*}{90} & $\begin{array}{l}\text { FIRST } \\
\text { MODE }\end{array}$ & 1.265 & 1.3473 & 6.50592885 & 1.2906 & 1.4588 & 13.032698 \\
\hline & $\begin{array}{l}\text { SECOND } \\
\text { MODE }\end{array}$ & 1.2831 & 1.4387 & 12.1268802 & 1.4529 & 1.6924 & 16.4842728 \\
\hline
\end{tabular}

Table 3.2. Non-dimensional in-plane frequency parameter of single-layer composite FFFF plates.

Further by using above properties and TRM methodology in various results for in-plane nondimensional frequency is calculated. For the square plate present results are compared with Ref.3 with stiffness ratio $E_{2} / E_{1}=1.5 \& 2.5$. Computed eigenvalues are presented in two tables according to the combination of clamped and free
ELK Asia Pacific Journals - Special Issue

ISBN: 978-81-930411-4-7

edge supports. For the FFFF condition this is depicted in Table 3.2 and for CCCC condition it is presented in Table 3.3.

\begin{tabular}{|c|c|c|c|c|c|c|c|}
\hline \multicolumn{2}{|c|}{$\begin{array}{l}\text { Angle } \\
\text { (Degree) }\end{array}$} & \multicolumn{3}{|c|}{$\begin{array}{c}\operatorname{CCCC}(b / a=1) \\
\text { E2/E1=1.5 }\end{array}$} & \multicolumn{3}{|c|}{$\begin{array}{c}\mathrm{CCCC}(\mathrm{b} / \mathrm{a}=1) \\
\mathrm{E} 2 / \mathrm{E} 1=2.5\end{array}$} \\
\hline & & Ref.3 & Present & Error (\%) & Ref.3 & Present & Error (\%) \\
\hline \multirow{2}{*}{$\mathbf{0}$} & $\begin{array}{l}\text { FIRST } \\
\text { MODE }\end{array}$ & 1.8329 & 1.84836 & 0.843472093 & 1.9156 & 2.0064 & 4.74002923 \\
\hline & $\begin{array}{l}\text { SECOND } \\
\text { MODE }\end{array}$ & 2.1175 & 1.96334 & - & 2.6132 & 2.3008 & $\begin{array}{r}- \\
11.9546916\end{array}$ \\
\hline \multirow{2}{*}{15} & $\begin{array}{l}\text { FIRST } \\
\text { MODE }\end{array}$ & 1.8558 & 1.80412 & - & 1.9215 & 1.8879 & $\begin{array}{r}- \\
1.74863388\end{array}$ \\
\hline & $\begin{array}{l}\text { SECOND } \\
\text { MODE }\end{array}$ & 2.114 & 1.98584 & -6.06244087 & 2.6088 & 2.3672 & - \\
\hline \multirow{2}{*}{30} & $\begin{array}{l}\text { FIRST } \\
\text { MODE }\end{array}$ & 1.8418 & 1.74136 & - & 1.9341 & 1.93912 & 0.25955225 \\
\hline & $\begin{array}{l}\text { SECOND } \\
\text { MODE }\end{array}$ & 2.1066 & 2.0052 & $\begin{array}{r}- \\
4.813443463\end{array}$ & 2.5998 & 2.4178 & -7.0005385 \\
\hline \multirow{2}{*}{45} & $\begin{array}{l}\text { FIRST } \\
\text { MODE }\end{array}$ & 1.8449 & 1.71556 & - & 1.9408 & 1.88736 & - \\
\hline & $\begin{array}{l}\text { SECOND } \\
\text { MODE }\end{array}$ & 2.1028 & 2.0092 & - & 2.5951 & 2.4244 & -6.5777812 \\
\hline \multirow{2}{*}{60} & $\begin{array}{l}\text { FIRST } \\
\text { MODE }\end{array}$ & 1.8418 & 1.74136 & $\begin{array}{r}- \\
5.453360843\end{array}$ & 1.9341 & 1.93912 & 0.25955225 \\
\hline & $\begin{array}{l}\text { SECOND } \\
\text { MODE }\end{array}$ & 2.1066 & 2.0052 & - & 2.5998 & 2.4178 & -7.0005385 \\
\hline \multirow{2}{*}{75} & $\begin{array}{l}\text { FIRST } \\
\text { MODE }\end{array}$ & 1.8558 & 1.80412 & - & 1.9215 & 1.8879 & $\begin{array}{r}- \\
1.74863388\end{array}$ \\
\hline & $\begin{array}{l}\text { SECOND } \\
\text { MODE }\end{array}$ & 2.114 & 1.98584 & -6.06244087 & 2.6088 & 2.3672 & 9.26096289 \\
\hline \multirow{2}{*}{90} & $\begin{array}{l}\text { FIRST } \\
\text { MODE }\end{array}$ & 1.8329 & 1.84836 & 0.843472093 & 1.9156 & 2.0064 & 4.74002923 \\
\hline & $\begin{array}{l}\text { SECOND } \\
\text { MODE }\end{array}$ & 2.1175 & 1.96334 & - & 2.6132 & 2.3008 & - \\
\hline
\end{tabular}

Table 3.3. Non-dimensional in-plane frequency parameter of single-layer composite CCCC plates.

From these tables, the influence of aspect ratio, material stiffness ratio, and angle of orthotropy and boundary conditions on the in-plane vibration 
ELK

Asia Pacific Journals

of single-layer generally orthotropic plates may be observed. First, it is noted that, with all the other parameters kept fixed, the frequency values decrease with increasing number of free edges. Moreover, for each boundary support condition, higher eigenvalues are obtained when the plate has higher stiffness ratio $E_{2} / E_{1}$ regardless of aspect ratio and angle of orthotropy. For both completely free and completely fixed square plates, i.e., $b / a=1.0$ i.e. Table 3. Due to symmetry, all the frequencies are symmetric with respect to $45^{\circ}$ orientation.

So this can be seen from both the Table $3 \& 4$; the present result is very much close to the previous work. This gives the validity of the method and can be used for the further parametric study. Although in FFFF results for $2^{\text {nd }}$ mode is varying as compared to other results but this can be treated in range. Rest all results are quite friendly compared to the previous one.

\section{Numerical study on isotropic plate}

For the isotropic plate where $E_{2} / E_{1}=1$, are considered for the study where elastic boundaries are applied and various effects are tabulated in present work. For the analysis the current approach is investigated for a square $\overline{E_{1}} \overline{E_{1}} \overline{E_{1}}$
ELK Asia Pacific Journals - Special Issue

ISBN: 978-81-930411-4-7

$\overline{E_{1}}$ plate with edge stiffness $k_{0}$ (i.e.

$k_{1}^{V}=k_{2}^{V}=k_{3}^{V}=k_{4}^{V}=k_{0} \quad$ and

$\left.k_{1}^{U}=k_{2}^{U}=k_{3}^{U}=k_{4}^{U}=0\right)$.

The first four in-plane dimensionless frequency parameters $\lambda=\frac{\omega a}{2} \sqrt{\frac{\rho\left(1+\sqrt{v_{12} v_{21}}\right)}{E_{1}}}$ are shown in Table 4.4 and Table 4.5 for two finite values of the dimensionless elastic edge stiffness:

$k^{*}=k_{0}(a / 2)\left(1-v^{2}\right) / E$.

From using data of Table $4.4 \& 4.5$ different kind of elastic edges (E1, E2, E12) and few values of the dimensionless elastic edge stiffness, $\mathrm{k}=1$, $10^{-2}, 10^{-4}, 10^{-6}$ are considered. It is observed from the calculated non-dimensional in-plane frequency parameter that in the isotropic plate with plate dimension aspect ratio $b / a=1$ i.e. $a$ square plate, the effects of E1-elastic edge is same as the E2-elastic edge conditions because of equal length and breadth of the plate. But when rectangular plate is considered where aspect ratio $\mathrm{b} / \mathrm{a}=2$ is taken for study, there is some variations in the effects of E1-elastic edge and E2-elastic edge. While considering E12-elastic edge conditions, this has relatively large value of nondimensional frequency parameter compared to E1and E2-edge. 


\begin{tabular}{|c|c|c|c|c|}
\hline \multicolumn{5}{|c|}{ E1 support $(b / a=1)$} \\
\hline $4^{\text {th }}$ Mode & & & 3.2915 & 3.215 \\
\hline $3^{\text {rd }}$ Mode & 5.125 & 4.4504 & 3.2143 & 3.2143 \\
\hline $2^{\text {nd }}$ Mode & 3.2143 & 3.2143 & 1.2601 & 1.2601 \\
\hline $1^{\text {st }}$ Mode & 1.2601 & 1.2601 & 1.136 & 1.2588 \\
\hline \multicolumn{5}{|c|}{ E2 support $(b / a=1)$} \\
\hline $4^{\text {th }}$ Mode & & & 3.2915 & 3.8244 \\
\hline $3^{\text {rd }}$ Mode & 5.125 & 4.4504 & 3.2143 & 3.3126 \\
\hline $2^{\text {nd }}$ Mode & 3.2143 & 3.2143 & 1.2601 & 1.4547 \\
\hline $1^{\text {st }}$ Mode & 1.2601 & 1.2601 & 1.136 & 1.3154 \\
\hline \multicolumn{5}{|c|}{ E12 support $(b / a=1)$} \\
\hline $2^{\text {nd }}$ Mode & 9.21 & 8.434 & 7.4011 & 8.161 \\
\hline $1^{\text {st }}$ Mode & 5.125 & 4.2986 & 3.8803 & 4.821 \\
\hline
\end{tabular}

Table 4.4. Non-dimensional in-plane frequency parameter of isotropic EEEE plates with aspect ratio $\mathrm{b} / \mathrm{a}=1$

\begin{tabular}{|c|c|c|c|c|}
\hline \multicolumn{5}{|c|}{ E1 support $(b / a=2)$} \\
\hline $4^{\text {th }}$ Mode & & & 2.8329 & 2.7547 \\
\hline $3^{\text {rd }}$ Mode & 6.482 & 2.8329 & 2.1794 & 2.1794 \\
\hline $2^{\text {nd }}$ Mode & 2.1794 & 0.92926 & 0.92926 & 0.92926 \\
\hline $1^{\text {st }}$ Mode & 0.92926 & 0.61767 & 0.61767 & 0.73413 \\
\hline \multicolumn{5}{|c|}{ E2 support $(b / a=2)$} \\
\hline $4^{\text {th }}$ Mode & & & 2.754 & 2.7953 \\
\hline $3^{\text {rd }}$ Mode & 6.517 & 2.268 & 2.268 & 2.5276 \\
\hline $2^{\text {nd }}$ Mode & 2.754 & 0.81092 & 0.81092 & 1.0852 \\
\hline $1^{\text {st }}$ Mode & 0.73537 & 0.73537 & 0.73537 & 0.80178 \\
\hline \multicolumn{5}{|c|}{ E12 support $(b / a=2)$} \\
\hline $2^{\text {nd }}$ Mode & 8.517 & 7.8621 & 2.8721 & 6.7079 \\
\hline $1^{\text {st }}$ Mode & 4.482 & 4.6049 & 2.6009 & 3.9778 \\
\hline
\end{tabular}

Table 4.5. Non-dimensional in-plane frequency parameter of isotropic EEEE plates with aspect ratio b/a=2.

For the orthotropic plates where elastic modulus have different value in different directions, all studies are done by taking stiffness ratio $E_{1} / E_{2}=$
2. All three previously discussed elastic edge conditions are considered and different values of 
the dimensionless elastic edge stiffness, $\mathrm{k}=1$,

$10^{-1}, 10^{-3}, 10^{-5}$ are also considered.

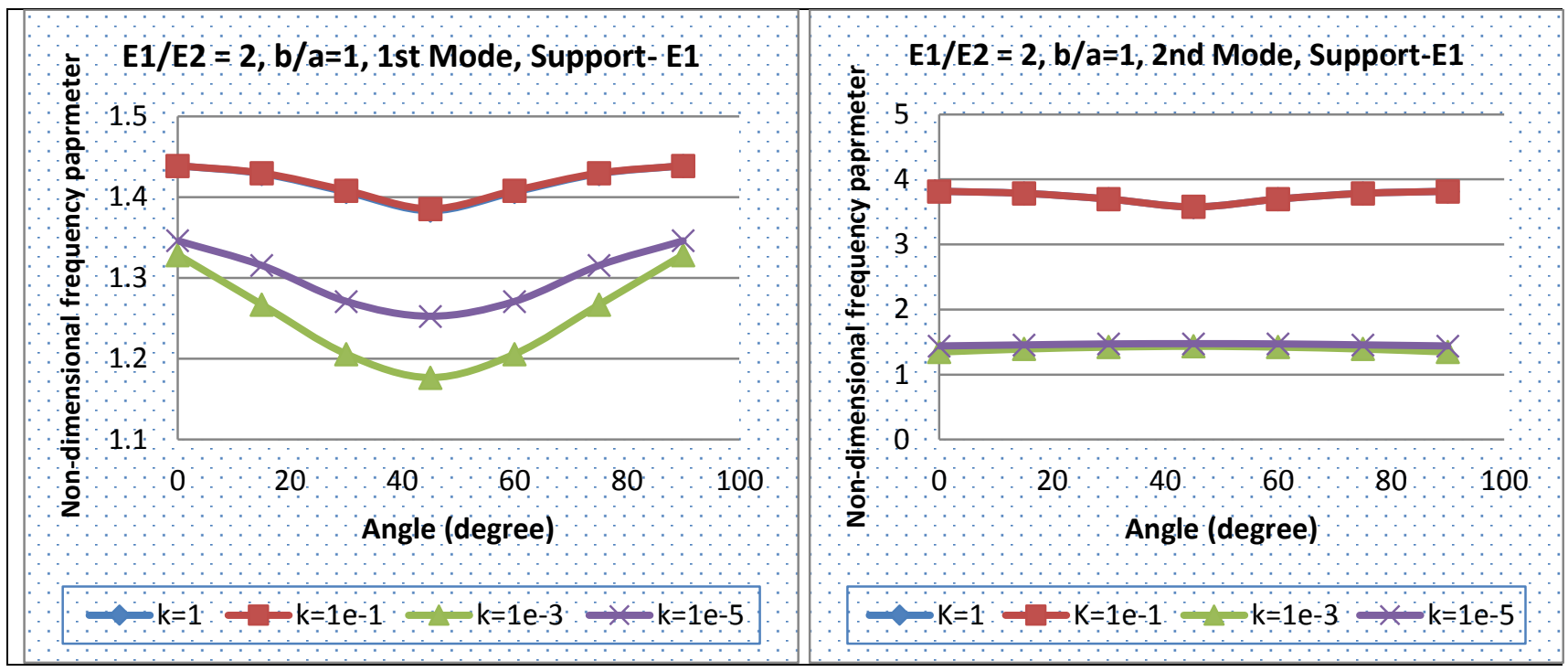

Figure 4.3. Variation of the first two frequency parameter and dimensionless elastic edge $\overline{E_{1}}$ square composite plate with $\frac{E_{1}}{E_{2}}=2$ with respect to degree of orthotropy

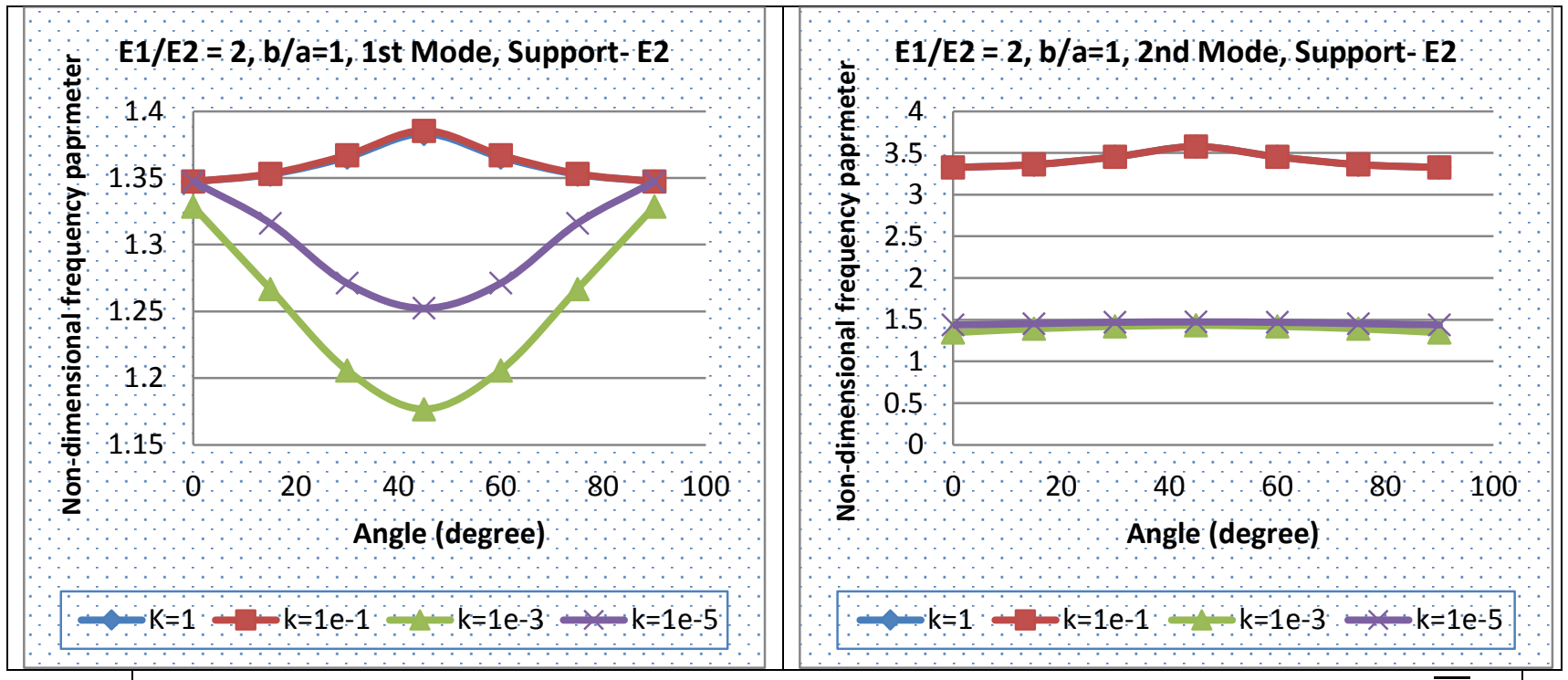

Figure 4.4. Variation of the first two frequency parameter and dimensionless elastic edge $\overline{E_{2}}$ square composite plate with $\frac{E_{1}}{E_{2}}=2$ with respect to degree of orthotropy 


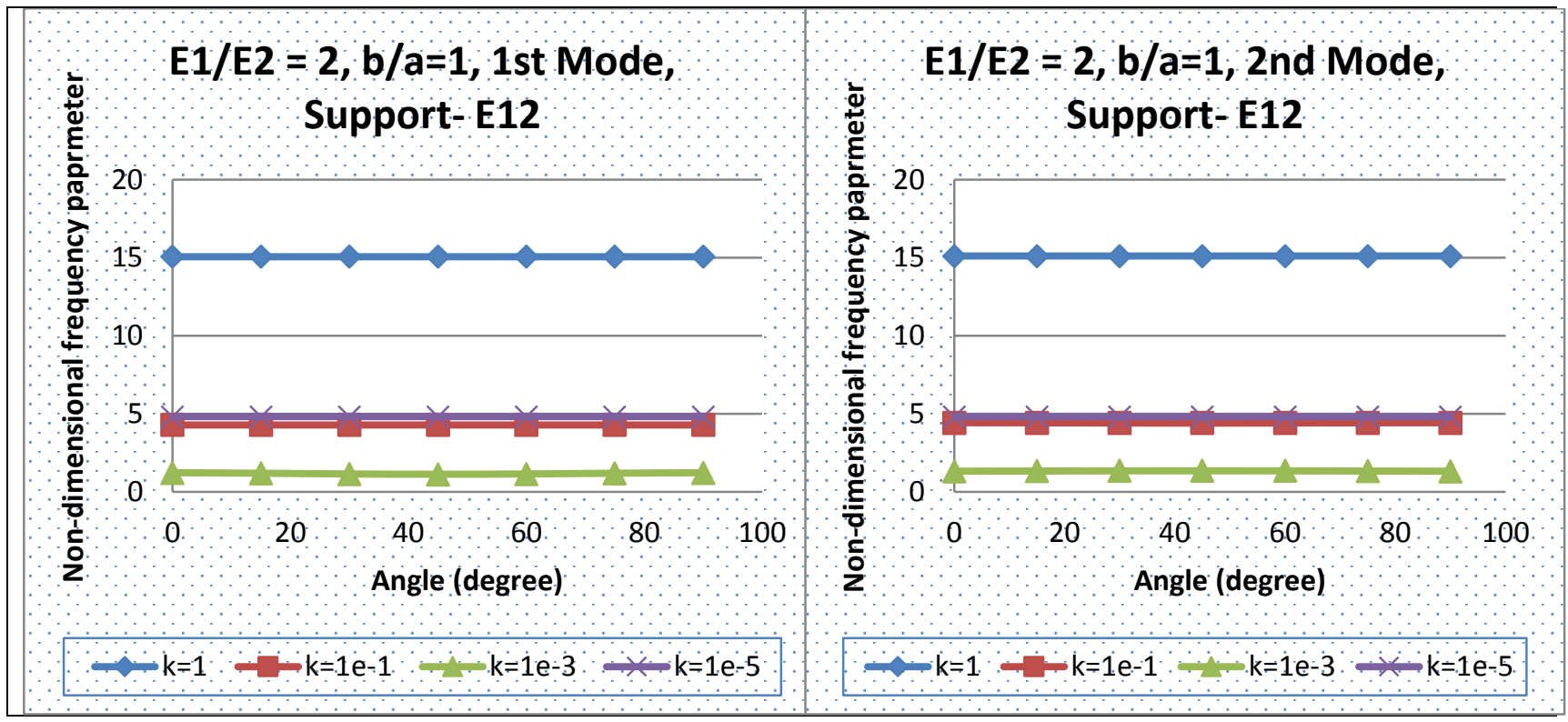

Figure 4.5. Variation of the first two frequency parameter and dimensionless elastic edge $\overline{E_{12}}$ square composite plate with $\frac{E_{1}}{E_{2}}=2$ with respect to degree of orthotropy

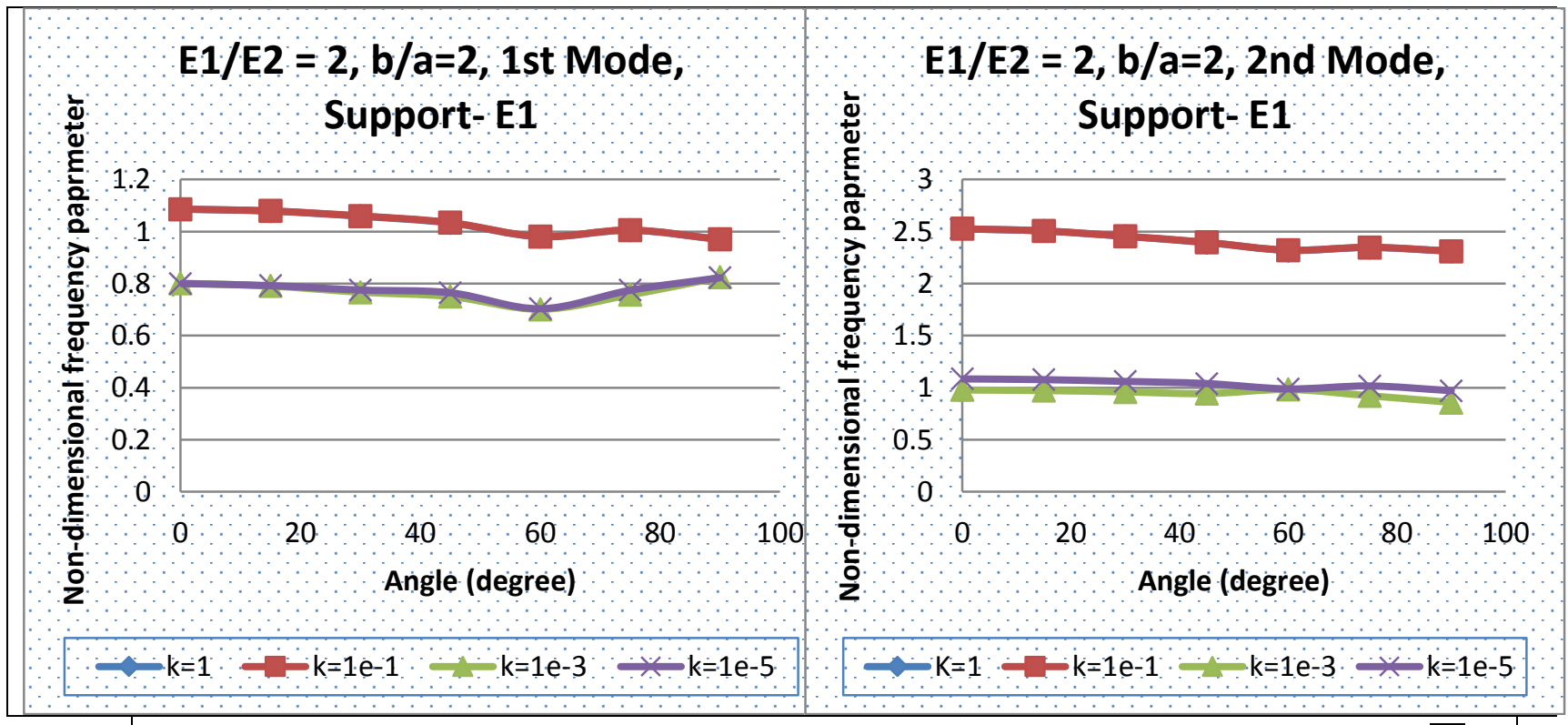

Figure 4.6. Variation of the first two frequency parameter and dimensionless elastic edge $\overline{E_{1}}$ rectangular composite plate with $\frac{E_{1}}{E_{2}}=2$ with respect to degree of orthotropy 


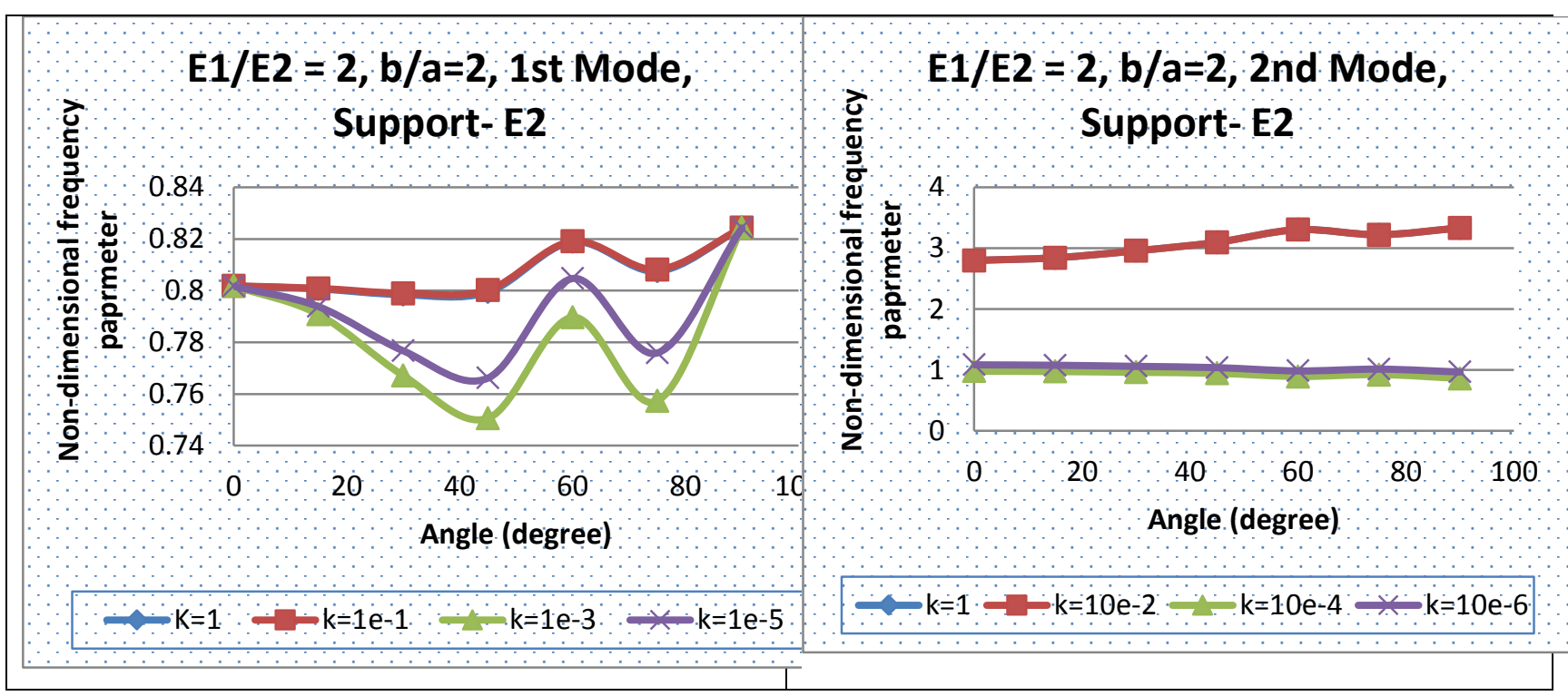

Figure 4.7. Variation of the first two frequency parameter and dimensionless elastic edge $\overline{E_{2}}$ rectangular composite plate with $\frac{E_{1}}{E_{2}}=2$ with respect to degree of orthotropy
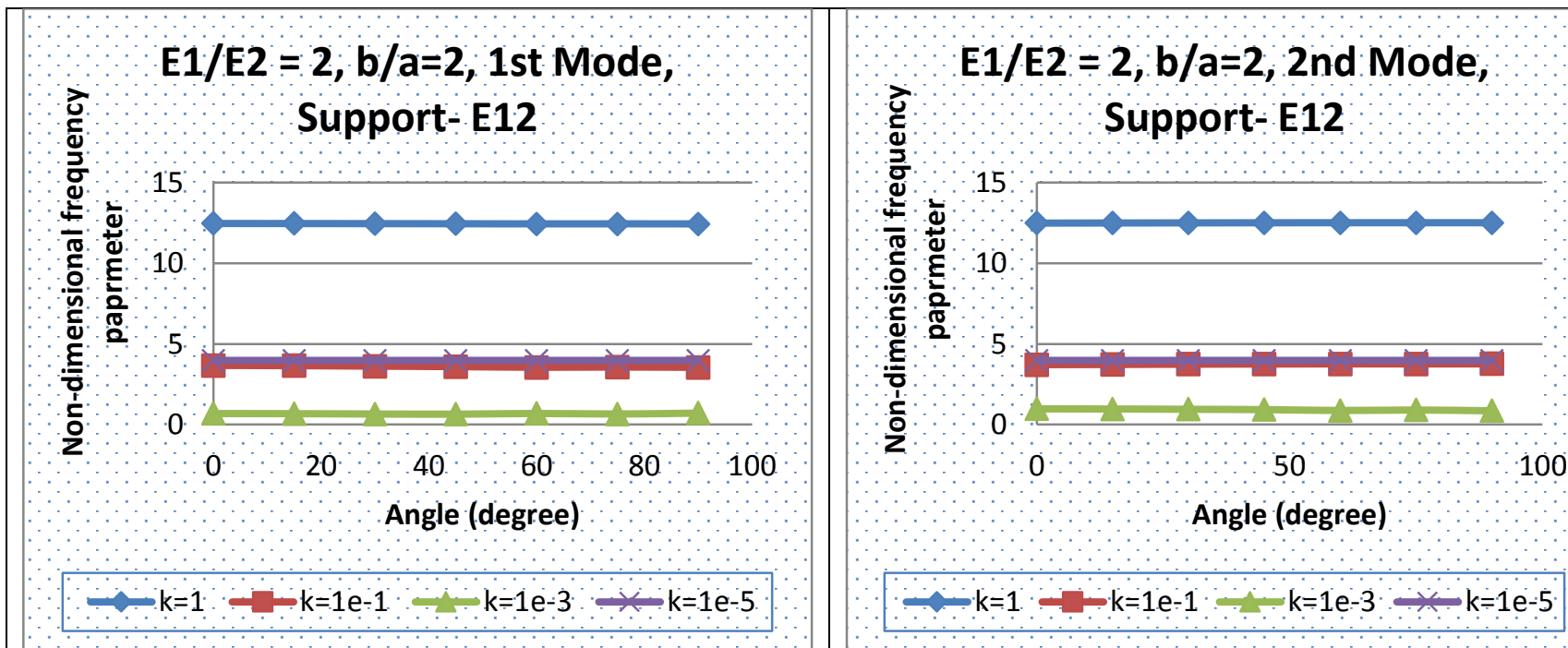

Figure 4.8. Variation of the first two frequency parameter and dimensionless elastic edge $\overline{E_{12}}$ rectangular composite plate with $\frac{E_{1}}{E_{2}}=2$ with respect to degree of orthotropy 
ELK

Asia Pacific Journals

Numerical study on multi-layer composite plate

\begin{tabular}{|c|c|c|c|c|c|}
\hline & & FRE & UENCI & $\overline{\text { ARAMI }}$ & \\
\hline & & & FFFF & CFCF & $\mathrm{CCCC}$ \\
\hline $\mathbf{b} / \mathbf{a}=\mathbf{1}$ & $(90 / 0) 2 \mathrm{~S}$ & $4^{\text {th }}$ & 3.0535 & 2.9378 & \\
\hline & & Mode & & & 5.6168 \\
\hline & & $3^{\text {rd }}$ & 2.4157 & 2.3160 & \\
\hline & & Mode & & & 4.4042 \\
\hline & & $2^{\text {nd }}$ & 1.1154 & .96926 & \\
\hline & & Mode & & & 1.51898 \\
\hline & & $1^{\mathrm{st}}$ & .99699 & .86661 & \\
\hline & & Mode & & & 1.3698 \\
\hline & $(90 / 02 / 90) \mathrm{S}$ & $4^{\text {th }}$ & 3.0535 & 7.2902 & \\
\hline & & Mode & & & 5.6168 \\
\hline & & $3^{\text {rd }}$ & 2.4157 & 5.3237 & \\
\hline & & Mode & & & 4.4042 \\
\hline & & $2^{\text {nd }}$ & 1.1154 & 3.0651 & \\
\hline & & Mode & & & 1.51898 \\
\hline & & $1^{\text {st }}$ & .99699 & 2.7405 & \\
\hline & & Mode & & & 1.3698 \\
\hline $\mathbf{b} / \mathbf{a}=\mathbf{2}$ & $(90 / 0) 2 \mathrm{~S}$ & $4^{\text {th }}$ & 2.0004 & 1.9329 & \\
\hline & & Mode & & & 3.7186 \\
\hline & & $3^{\text {rd }}$ & 1.9888 & 1.9041 & \\
\hline & & Mode & & & 3.6132 \\
\hline & & $2^{\text {nd }}$ & .85628 & .74678 & \\
\hline & & Mode & & & 1.18066 \\
\hline & & $1^{\mathrm{st}}$ & .60198 & .52013 & \\
\hline & & Mode & & & 0.81118 \\
\hline & $(90 / 02 / 90) \mathrm{S}$ & $4^{\text {th }}$ & 2.0004 & 6.1124 & \\
\hline & & Mode & & & 3.7186 \\
\hline & & $3^{\text {rd }}$ & 1.9888 & 4.0212 & \\
\hline & & Mode & & & 3.6132 \\
\hline & & $2^{\text {nd }}$ & .85628 & 2.3615 & \\
\hline & & Mode & & & 1.18066 \\
\hline & & $1^{\text {st }}$ & .60198 & 1.6448 & \\
\hline & & Mode & & & 0.81118 \\
\hline & & & & & \\
\hline
\end{tabular}

Table 4.1: Non-dimensional in-plane frequency
ELK Asia Pacific Journals - Special Issue

ISBN: 978-81-930411-4-7

parameter of multi-layer composite plates.

After validating the results for the single-layer composite plates, work is next extended to multilayer composite plates. Two kinds of different laminates (90/0)2s and 90/0/0/90)s are taken. Both are symmetric in nature and each lamina thickness is $2.5 \mathrm{~mm}$. Three different kind of basic boundary conditions are considered, FFFF, CFCF and CCCC. This work is done for aspect ratio, $\mathrm{b} / \mathrm{a}=1,2$. The non-dimensional frequencies for four modes are tabulated in the following Table 4.1 .

\section{CONCLUSIONS}

This paper has presented a reasonably comprehensive set of numerical results for inplane free motion of single-layer generally orthotropic and symmetrically laminated rectangular plates with an arbitrary combination of clamped and free boundaries. An analysis has done on in-plane vibration analysis of rectangular plates with uniform elastically restrained edges. Accurate analytical-type solutions have been obtained by a highly stable trigonometric set of trial functions in the Ritz method.

Following observations and conclusions we made on the study of In-plane vibrations. 
ELK

Asia Pacific Journals

1. First, it is noted that, with all the other parameters like orthotropic angle, aspect ratio of the plate, material stiffness ratio kept fixed, the frequency values decrease with increasing number of free edges.

2. Moreover, for each boundary support condition, higher eigenvalues are obtained when the plate has higher stiffness ratio $E_{2} / E_{1}$ regardless of aspect ratio and angle of orthotropy.

3. For square composite plates, the effects of $\overline{E_{1}}$ and $\overline{E_{2}}$ are same. While for rectangular plates $\overline{E_{1}}$ and $\overline{E_{2}}$ elastic edge have different effects on the In-plane frequency.

4. Calculated non-dimensional In-plane frequency parameter on the effect of $\overline{E_{1}}$ elastic edge and $\overline{E_{2}}$ elastic edge are similar and value sometime overlaps each other. This possibility is much for the $1^{\text {st }}$ mode than the $2^{\text {nd }}$ mode and so on while $\overline{E_{12}}$ elastic edge offers large value of nondimensional In-plane frequency.

5. It is observed that dimensionless elastic edge stiffness value $\left(\mathrm{k}^{*}\right)$ has significant effects on the non-dimensional frequency parameter. As the value of dimensionless
ELK Asia Pacific Journals - Special Issue

ISBN: 978-81-930411-4-7

elastic edge value is increasing it is shifted towards fully restrained edges.

6. Angle of orthotropy has varied results for different cases studied. There is no such similar pattern. But boundary condition when keeping same and other parameters like material stiffness ratio and dimensionless elastic edge stiffness value varies and values of non-dimensional frequency parameter changes but follows similar pattern can be seen in the graphs.

\section{REFERENCES}

[1] D.J. Gorman, Exact solutions for the free in-plane vibration of rectangular plates with two opposite edges simply supported. J Sound Vib, 294 (2006), pp. 131-161.

[2] Y.F. Xing, B. Liu, Exact solutions for the free in-plane vibrations of rectangular plates. Int J MechSci, 51 (2009), pp. 246-255.

[3] Lorenzo Dozio, In-plane free vibrations of single-layer and symmetrically laminated rectangular composite plates. Composite Structures, Volume 93, Issue 7, June 2011, Pages 1787-1800

[4] Y. Kobayashi, G. Yamada, S. Honma, In-plane vibration of point-supported rectangular plates.J Sound Vib, 126 (1988), pp. 545-549

[5] N.S. Bardell, R.S. Langley, J.M. Dunsdon ～， On the free in-plane vibration of isotropic rectangular plates. $J$ Sound Vib, 191 (1996), pp. 459-467

[6] A.V. Singh, T. Muhammad, Free in-plane vibration of isotropic non-rectangular plates. J Sound Vib, 273 (2004), pp. 219-231 
[7] R.L. Woodcock, R.B. Bhat, I.G. Stiharu, Effect of ply orientation on the in-plane vibration of single-layer composite plates. J Sound Vib, 312 (2008), pp. 94-108

[8] G. Wang, N.M. Wereley, Free in-plane vibration of rectangular plates. AIAA J, 40 (2002), pp. 953-959

[9] D.J. Gorman, Vibration analysis of plates by the superposition method. World Scientific, Singapore (1999)

[10] D.J. Gorman, Free in-plane vibration analysis of rectangular plates by the method of superposition.J Sound Vib, 272 (2004), pp. 831-851

[11] D.J. Gorman, Accurate analytical type solutions for the free in-plane vibration of clamped and simply supported rectangular plates. J Sound Vib, 276 (2004), pp. 311-333

[12] D.J. Gorman, Free in-plane vibration analysis of rectangular plates with elastic support normal to the boundaries. J Sound Vib, 285 (2005), pp. 941-966

[13] D.J. Gorman, Accurate in-plane free vibration analysis of rectangular orthotropic plates. J Sound Vib, 323 (2009), pp. 426-443

[15] J. Du, W.L. Li, G. Jin, T. Yang, Z. Liu, An analytical method for the in-plane vibration analysis of rectangular plates with elastically restrained edges.J Sound Vib, 306 (2007), pp. 908-927

[16] O. Beslin, J. Nicolas, A hierarchical functions set for predicting very high order plate bending modes with any boundary conditions. J Sound Vib, 202 (1997), pp. 633-655

[17] Dozio L, On the use of the trigonometric Ritz method for general vibration analysis of rectangular Kirchhoff plates. Thin Wall Structure 2011; pp49:129-44.

[18] L. Dozio, Free in-plane vibration analysis of rectangular plates with arbitrary elastic boundaries. Mech Res Commun, 37 (2010), pp. 627-635. 